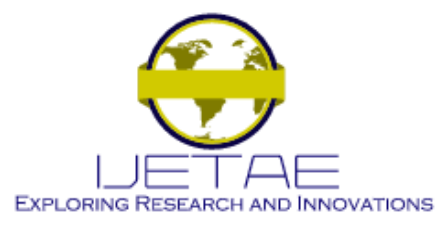

International Journal of Emerging Technology and Advanced Engineering

Website: www.ijetae.com (ISSN 2250-2459, ISO 9001:2008 Certified Journal, Volume 10, Issue 07, July 2020)

\title{
Verification and Validation of a 2x2 Subchannel CFD Model for a PWR Spacer Grid Evaluation Employing LDV Measurements
}

\author{
Higor F. P. Castro ${ }^{1}$, Guilherme. A. M. Vidal ${ }^{2}$, Rebeca. C. Gonçalves ${ }^{3}$, André. A. Campagnole dos Santos ${ }^{4}$, \\ Maria. A. F. Veloso 5 \\ 1,3,4,5 Universidade Federal de Minas Gerais, Av. Presidente Antônio Carlos, 6627 - 31270-941, Belo Horizonte, MG, Brazil \\ ${ }^{2,3,4}$ Centro de Desenvolvimento da Tecnologia Nuclear, Comissão Nacional de Energia Nuclear, Av. Presidente Antônio Carlos, \\ 6627 - 31270-941, Belo Horizonte, MG, Brazil
}

\begin{abstract}
A Pressurized Water Reactor (PWR) core is composed of fuel rod bundles kept separate and in square arrangements by spacer grids placed along its length. These spacers are responsible for the improvement of the water mixture between and within the subchannels (space formed in between four rods), increasing the heat transfer and turbulence. Experimental and Computational Fluid Dynamics (CFD) studies have been performed to achieve a better understanding of the water flow dynamics and improve the design of this complex geometry. In this work, experimental velocity data obtained by the 2D Laser Doppler Velocimeter (LDV) technique is compared to CFD data for its validation. Measurements are performed at an experimental facility with a $5 \times 5$ rod bundle with split vane spacer grids. The experimental data were obtained by a top down measurement along two subchannels at three different positions downstream the spacer grid. Simulations are performed using a $2 \times 2$ reduced domain model that can save computational time and cost. The objective of this comparison is to assess if this simplified model is able to predict the average flow behavior and be used as a valid approach for initial design evaluation. Verification and Validation $(\mathrm{V} \& \mathrm{~V})$ of the CFD simulation using three systematically refined meshes was done to assess numerical and validation uncertainties. Results show a qualitative agreement between simulations and experimental results. Simplifications of the numerical model and limitations of the employed CFD modeling limit the applicability of the presented method, however, results indicate that the approach could be used as an initial design evaluation tool.
\end{abstract}

Keywords - CFD, Nuclear Reactor, PWR, Spacer Grid, $\mathbf{V} \& \mathbf{V}$.

\section{INTRODUCTION}

The Pressurized Water Reactor (PWR) is the most common nuclear reactor used in the world for energy generation, with 441 active reactors in June 2020 [1]. The PWR core is composed of fuel elements that are long arrays of fuel rods bundled together in equally spaced square patterns with an average of $16 \times 16$ rods per bundle.
The pitch between rods is kept constant using honeycomb like spacer grids placed along the length. This is crucial to allow water to flow in between the rods and transfer heat. Top and bottom nozzles complete the fuel assembly.

The spacer grids of PWR fuel assemblies play a critical role in both structural and thermal-hydraulic performance. Springs and supports for rods placed within the structure of the spacer ensure the structural integrity of the bundle, avoiding relative movement during operation and excessive vibration. Mixing devices, like mixing vanes, are present at the downstream extremity of the grid to promote enhanced heat exchange to the water from the fuel rods through increased turbulence and lateral motion in between rods. Therefore, it is extremely important to understand the mixing phenomena caused by the spacer grids to develop better nuclear fuel elements for PWR reactors.

The study of the flow induced by spacer grids promoted many studies in the past decades, both experimental and theoretical [2, 3, 4 and 5]. One of the trends in recent years is to employ advanced computational methods, such as Computational Fluid Dynamics (CFD), to improve understanding of the fluid flow dynamics caused by spacer grids [6, 7, 8 and 9].

CFD codes can be open source, such as OpenFOAM [10], or not, such as ANSYS CFX [11]. They can give important 3D spatial details of the flow and allow in-depth analysis of velocity, pressure and temperature fields needed for a better comprehension of flow behavior along a PWR fuel element.

This paper describes efforts in an ongoing project which aims at the Verification and Validation (V\&V) of a CFD numerical simulation procedure of the water flow through spacer grids. Validation of the simulation data will be obtained by comparison to experimental tests made at the Thermal-hydraulics and Neutronics Laboratory (LTHN) of the Nuclear Technology Development Center (CDTN) of Brazil. 


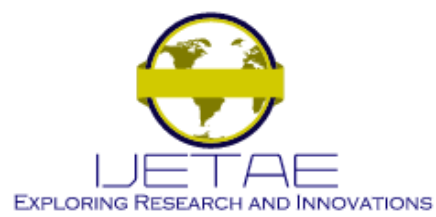

International Journal of Emerging Technology and Advanced Engineering

Website: www.ijetae.com (ISSN 2250-2459, ISO 9001:2008 Certified Journal, Volume 10, Issue 07, July 2020)

In this work, a $2 \times 2$ subchannel (water channels in the space surrounded by four rods) with a split vane spacer grid was simulated and compared to velocity measurements performed in a $5 \times 5$ rod bundle using a $2 \mathrm{D}$ LDV (Laser Doppler Velocimetry) in top down position. The measurement position allows the assessment of both lateral mixing velocity components.

The main objective of this work is to verify if it is possible to obtain reliable CFD results from a reduced $2 \times 2$ domain for initial design assessment. A full $\mathrm{V} \& \mathrm{~V}$ procedure was employed to evaluate numerical and validation uncertainties [12].

\section{EXPERIMENTAL METHODOLOGY}

The experimental facility consists of a $5 \times 5$ rod bundle with four split vane spacer grids equally spaced along the rods. The bundle is held within a stainless steel housing with two acrylic windows on opposing sides and one on the top that allows the measurement of velocity profiles using a 2D LDV, as can be seen in Fig. 1. The system also includes temperature and pressure measurements to determine fluid properties. Flow rate is determined using an orifice plate flow meter. The water in the tank is maintained at a constant $25.0 \pm 0.5{ }^{\circ} \mathrm{C}$ using an indirect chiller system. The 1000 liters of water in the tank guarantees high thermal inertia which facilitates the temperature control, avoiding fast temperature increases during the testes due to the 15 HP pump.

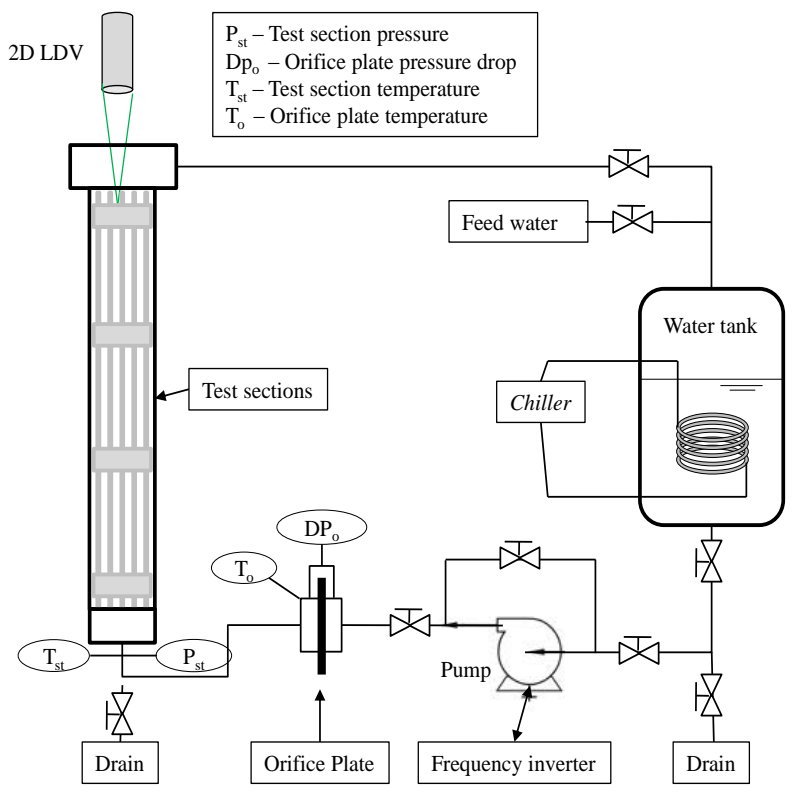

Figure 1: Hydraulic Circuit [13].
The top down measurement position allows data from the two lateral velocities to be measured simultaneously in and between subchannels as shown in Fig. 2 .

In this study, to validate the $2 \times 2$ CFD model, a line across one of the central subchannels was measured. Five independent measurements of the profile were performed to for repetitivity of the experiment and experimental uncertainty evaluation.

All presented velocity results are normalized by the bulk rod bundle free flow area axial velocity $\langle\bar{w}\rangle$. Normalized lateral velocity $(\bar{u} /\langle\bar{w}\rangle)$ expanded uncertainty for a $95 \%$ confidence interval for both velocity directions was in average $\pm 0.02[-]$.

For a better comprehension of the flow, measurements were made at three distinct heights, $z$, downstream the spacer grid. Values of these positions were normalized by the pitch between rods, $\mathrm{p}$. The $z / p$ positions measured were: $1.22,2.44$ and 7.31 .

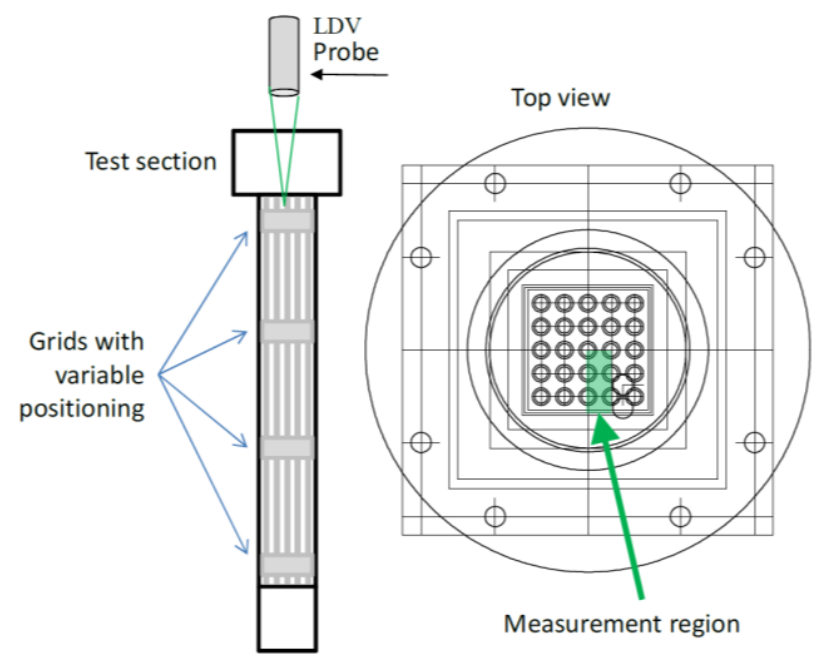

Figure 2: Measurement Region [13].

All tests were performed at Reynolds numbers $\sim 54 \times 103$. More details of the experimental measurement procedure can be obtained in the work by Castro et al. [13].

\section{NUMERICAL METHODOLOGY}

For the numerical simulation, the as-built geometry was drawn using Solidworks [14]. All the details of the grid used in the test section were included in the CAD model to obtain as reliable results as possible. The only simplification is the domain size. It includes only a $2 \times 2$ subchannel or a $3 \times 3$ rod bundle domain. Figure 3 shows details of the geometrical model created. 


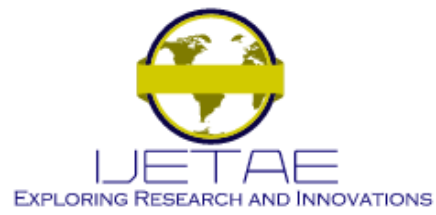

International Journal of Emerging Technology and Advanced Engineering Website: www.ijetae.com (ISSN 2250-2459, ISO 9001:2008 Certified Journal, Volume 10, Issue 07, July 2020)

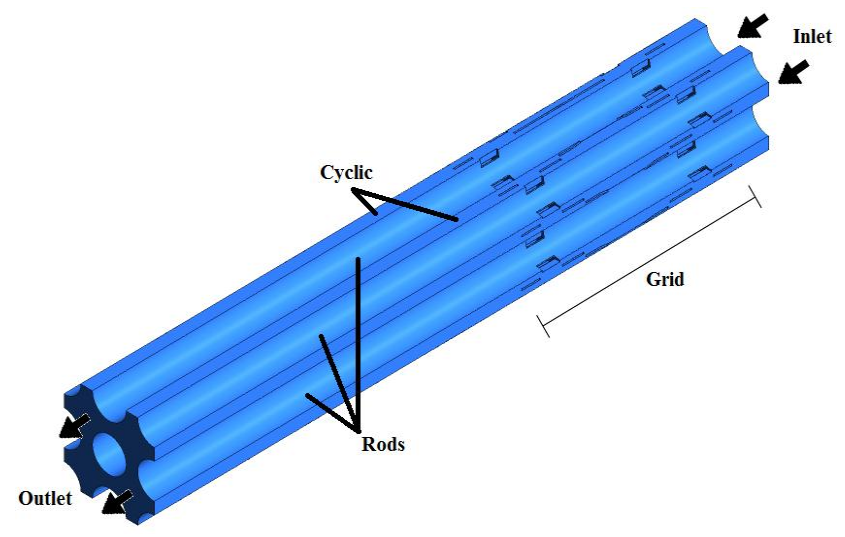

Figure 3: Geometry and boundary conditions.

The boundary conditions, as can be seen in Fig. 3, consisted of a flow rate inlet, a pressure outlet, smooth walls for the spacer grid and rods and cyclic conditions to allow flow to exit and re-enter the domain from the opposite side. The cyclic condition is possible due to the geometrical symmetry of the surrounding subchannels in the $5 \times 5$ actual domain.

Applied boundary conditions are presented in Tab. I. The simulations initial conditions were based in the experimental test, using the same flow velocity and water temperature, which was considered constant and defined according to the table of IAPWS-IF97 [15].

TABLE I

BOUNDARY CONDITIONS FOR THE SPACER GRID.

\begin{tabular}{|c|c|c|}
\hline Boundary & Condition & Values \\
\hline \multirow{2}{*}{ Inlet } & $\begin{array}{c}\text { Uniform } \\
\text { dimensionless axial } \\
\text { velocity }\end{array}$ & $1[-]$ \\
\cline { 2 - 3 } & $\begin{array}{c}\text { Turbulence intensity } \\
\text { Outlet }\end{array}$ & $\begin{array}{c}\text { Average relative } \\
\text { static pressure }\end{array}$ \\
\hline $\begin{array}{c}\text { Rods and grid } \\
\text { surfaces }\end{array}$ & No-slip walls & Smooth wall \\
\hline Cyclic & Cyclic & Translational \\
\hline
\end{tabular}

The mesh generation and the simulation were done using the commercial CFD code Ansys CFX [11]. To obtain a better mesh discretization in the grid region and reduce the computational cost, a hybrid hexahedral/tetrahedral mesh was generated instead of only a tetrahedral mesh, similar to what was done in the work by Wang et al. [16]. Therefore a hexahedral mesh was used along the geometry, except in the grid region, as can be seen in Fig. 4. At the spacer region, the mesh was a refined tetrahedral mesh, as in [16, $17,18]$.
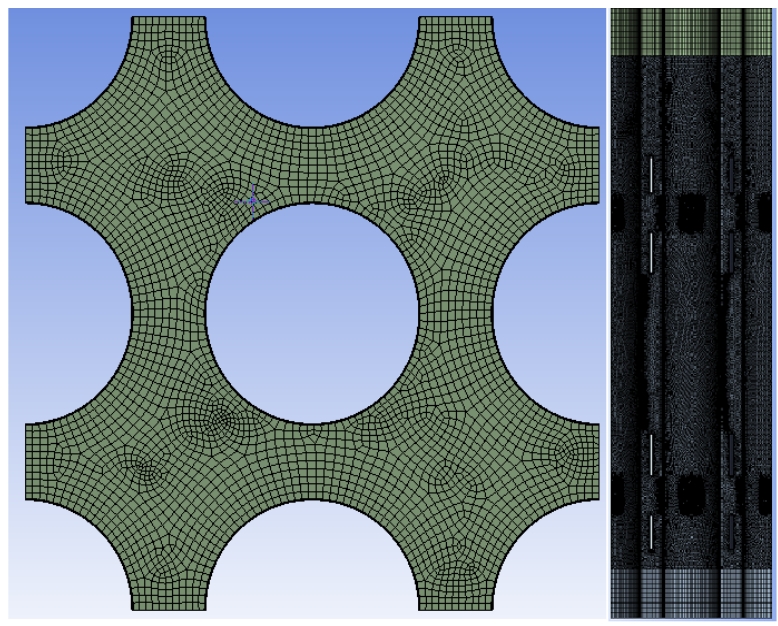

Figure 4: Top and side view of the mesh.

In this work, three systematically refined meshes were generated to evaluate numerical uncertainty applying the V\&V GCI (Grid Convergence Index) method [12]. Mesh element number details are presented in Tab. II. The refinement ratio, $r$, is defined as the average mesh length, $h$, of the previous coarser mesh divided by the $h$ of the current mesh.

TABLE III

MESHES USED IN THE STUDY.

\begin{tabular}{|c|c|c|}
\hline Mesh & Nodes / Elements & $\begin{array}{c}\text { Refinement } \\
\text { ratio (r) }\end{array}$ \\
\hline Mesh 3 & $7587675 / 24362635$ & - \\
\hline Mesh 2 & $\begin{array}{c}14870942 / \\
54749086\end{array}$ & 1.25 \\
\hline Mesh 1 & $\begin{array}{c}24082393 / \\
93820663\end{array}$ & 1.17 \\
\hline
\end{tabular}

Numerical uncertainty due to discretization can be determined using the GCI method, however, the total numerical uncertainty is also highly influenced by input parameters [12]. To evaluate input uncertainty dozens of simulations are required. Due to computational and time constraints, input uncertainty was not evaluated in this work and is suggested for future studies.

Second order discretization schemes were used for all RANS equations terms. The standard $\mathrm{k}-\varepsilon$ turbulence model was used. Simulations were run in steady state conditions. And the convergence residual target was set to $10^{-7}$ of the averaged RMS for the monitored variables. 


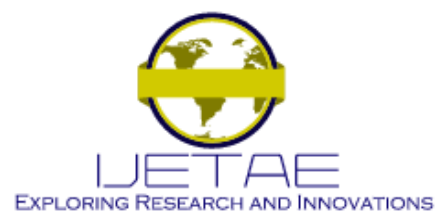

International Journal of Emerging Technology and Advanced Engineering Website: www.ijetae.com (ISSN 2250-2459, ISO 9001:2008 Certified Journal, Volume 10, Issue 07, July 2020)

\section{RESULTS}

The velocity fields obtained in the simulations were compared against the experimental tests. To evaluate the velocity profile, a line across the middle of one subchannel was evaluated, as can be seen in Fig. 5. Methodical positioning was necessary to ensure positioning agreement between numerical and experimental results.

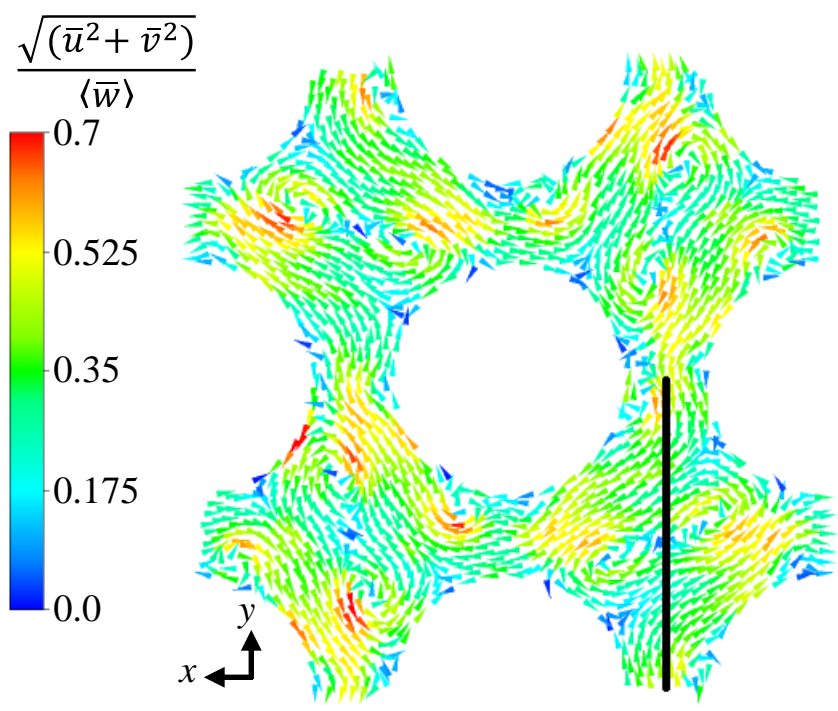

Figure 5: Velocity field and velocity line in study at height $\mathrm{z} / \mathrm{p}=\mathbf{1 . 2 2}$.

Fig. 5 also shows the lateral velocity resulting field normalized by the bulk axial velocity $\langle\bar{w}\rangle$. The figure reveals that as expected the modeled spacer grid generates located vortices and turbulence, creating swirl and crossflow inside and between subchannels.

To verify the numerical solution, the GCI method was employed using the results obtained for the three meshes generated for this study. The obtained data was evaluated at the described line across a subchannel shown in Fig. 5.

Results for the velocity profiles of the velocity component in direction $x$ are shown in Fig. 6 for all simulated meshes. Velocity profiles for all simulated meshes show very small variations for all evaluated heights.
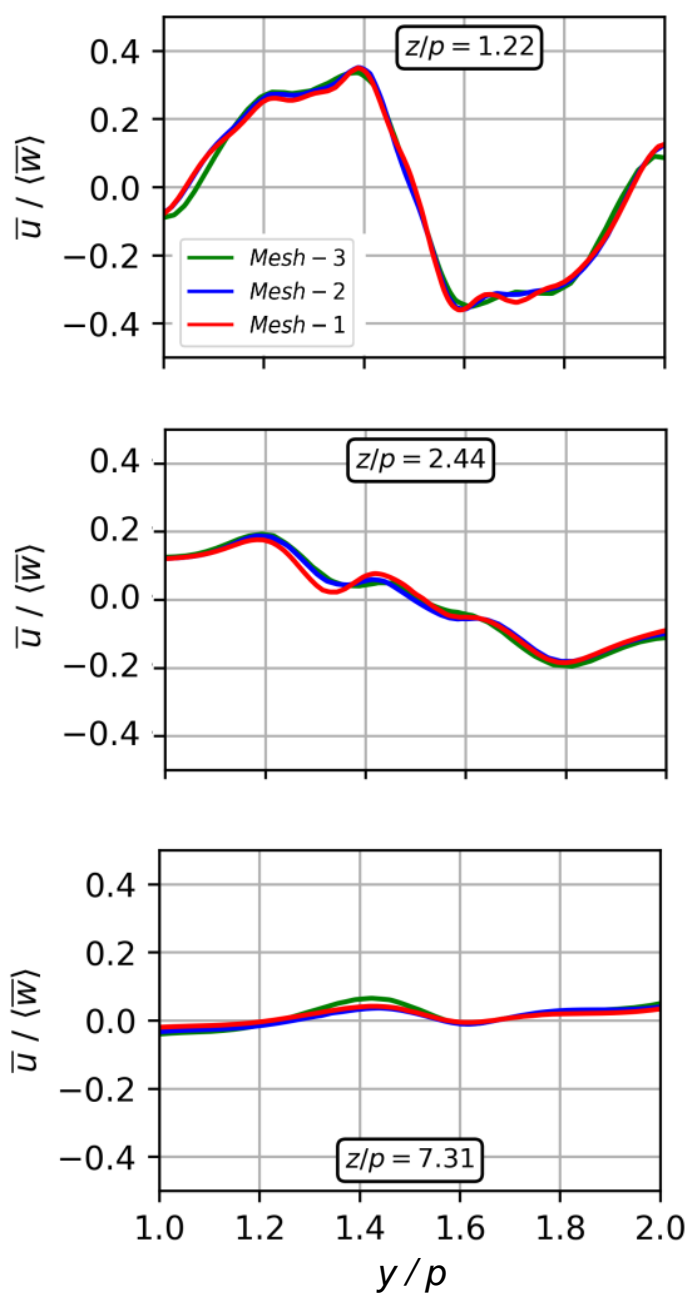

Figure 6: Numerical lateral velocity profile.

As a result of the observed convergence of results, predicted GCI numerical uncertainty due to mesh discretization was small along most of the profile. The average normalized value of uncertainty was $\pm 0.02[-]$. This value is the same average uncertainty that was observed for the experimental results. 


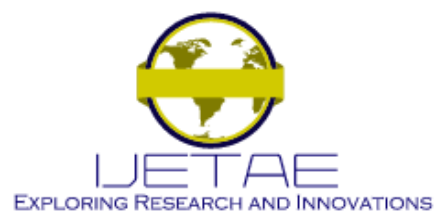

International Journal of Emerging Technology and Advanced Engineering

Website: www.ijetae.com (ISSN 2250-2459, ISO 9001:2008 Certified Journal, Volume 10, Issue 07, July 2020)

Numerical and experimental results were compared for all evaluated heights in Fig. 7. Uncertainties are also presented in the figure. In the position nearest to the spacer, $z / p=1.22$, peak magnitude of the lateral velocity component is over predicted by the numerical model. Also, an experimentally observed change of flow direction near the rod gap at $y / p=2$ is not predicted in the simulation.

Further from the grid, at $z / p=2.44$, results shown in Fig. 7 do not agree near the first rod at $y / p=1$, however, there is agreement in the remaining profile.

At the evaluated position furthest from the grid, at $z / p=$ 7.31 , both velocity profiles agree well within uncertainty bounds.

As a general observation, velocity profiles presented in Fig. 7 shows that the numerical model was able to capture the underlying flow movement and predict the correct rate of lateral flow decay as the distance from the grid increases.

Results indicate that, although a reduced $2 \times 2$ simulation domain has limitations in regards to predicted velocity profiles, the simplification is valid for initial assessments of design characteristics of spacer grids and their effect on flow.
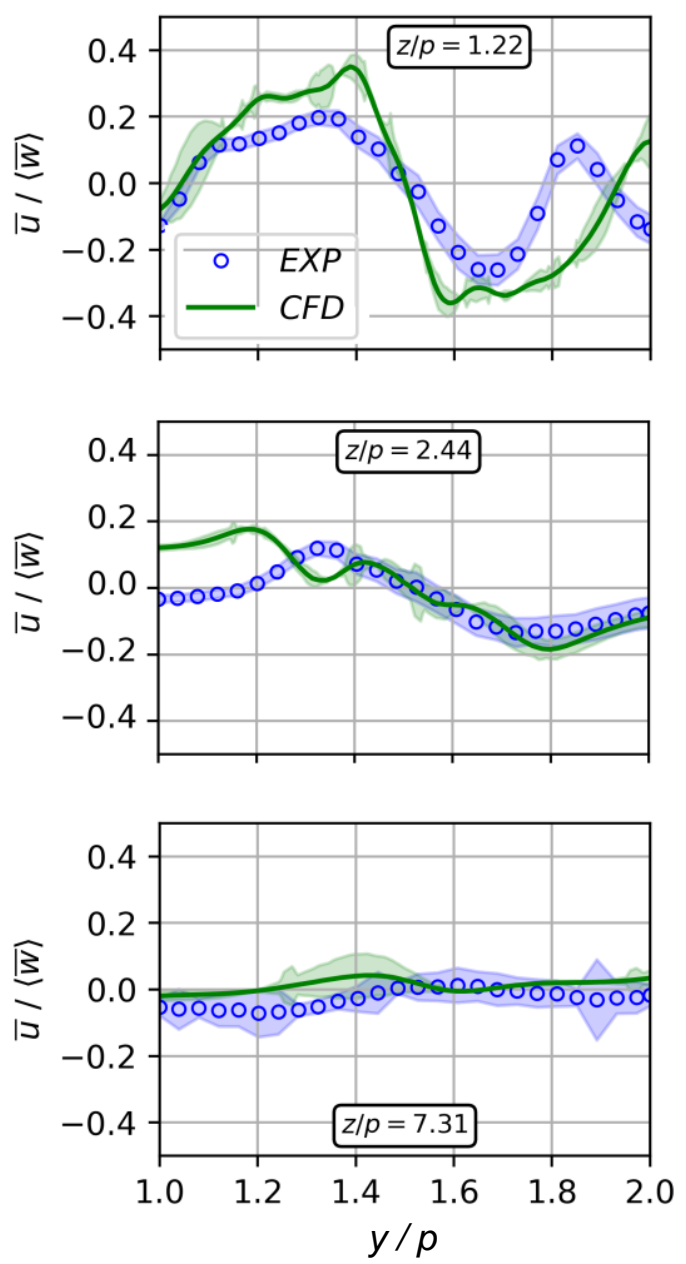

Figure 7: Numerical $x$ Experimental lateral velocity profile. 


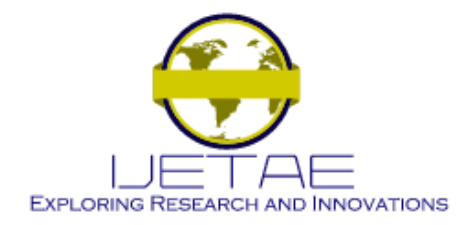

\section{International Journal of Emerging Technology and Advanced Engineering Website: www.ijetae.com (ISSN 2250-2459, ISO 9001:2008 Certified Journal, Volume 10, Issue 07, July 2020)}

\section{CONCLUSION}

In this work, a $2 \times 2$ rod bundle CFD model was evaluated. A verification procedure based on GCI method was performed to assess numerical discretization uncertainty. Experimental velocity measurements on a $5 \times 5$ bundle were performed to validate the CFD model.

Results indicate that the employed simplified CFD model can be used for initial design evaluation as it can predict overall behavior and decay of lateral movement downstream the spacer grid. However, caution should be taken as the model was unable to show some of the secondary motions present near the rods. Moreover, it also over predicted lateral motion near the grid, which makes the model less conservative. More lateral motion would mean more heat exchange which does not reflect reality and goes against safety for design evaluation. These differences can be attributed to the simplification of the domain and the used models, in particular the standard $\mathrm{k}-\varepsilon$ turbulence model.

Further studies are required to assess how reliable the proposed CFD model is. Evaluation of different grid designs and larger comparison databases are necessary. Also, model variations, in particular, turbulence models should be assessed to obtain increased accuracy.

The proposed CFD model and presented experimental setup showed great potential for the study of spacer grid design. In future work, more in depth analysis will be performed, evaluating different designs and CFD model variations.

\section{Acknowledgment}

This research project is supported by the following Brazilian institutions: Universidade Federal de Minas Gerais (UFMG), Nuclear Technology Development Center (CDTN), Brazilian Nuclear Energy Commission (CNEN), Research Support Foundation of the State of Minas Gerais (FAPEMIG) and Brazilian Council for Scientific and Technological Development (CNPq) project 427868/20165 and Coordenação de Aperfeiçoamento de Pessoal de Nível Superior (CAPES).

\section{REFERENCES}

[1] IAEA (International Atomic Energy Agency), PRIS - Power Reactor Information System, Available: http://www.iaea.org/pris/, 02 of July, (2020).

[2] Yao, S. C., Hochreiter, L. E., Leech, W. J., "Heat transfer augmentation in rod bundles near grid spacers", Journal of Heat Transfer, 104, pp. 76-81, (1982).

[3] Karoutas, Z., Gu, C., Sholin, B., "3-D Flow analyses for design of Nuclear Fuel Spacer", Proceedings of the 7th International Meeting on Nuclear Reactor Thermal-hydraulics NURETH-7, New York, USA, September 10-15, vol. 1, pp. 3153-3174, (1995).
[4] Kim, K. Y., Seo, J. W., "Shape optimization of a mixing vane in a subchannel of nuclear reactor", Journal of Nuclear Science and Technology, 41, pp. 641-644, (2004).

[5] In, W. K., Chun, T. H., Shin, C. H., Oh, D.S., "Numerical computation of heat transfer enhancement of a PWR rod bundle with mixing vane spacers", Nuclear Technology, 161, pp. 69-79, (2008).

[6] Chen, D., Xiao, Y., Xie, S., Yuan, D., Lang, X., Yang, Z., Lu, Q., "Thermal-hydraulic performance of a 5 x 5 rod bundle with spacer grid in a nuclear reactor", Applied Thermal Engineering, 103, 14161426, (2016).

[7] Agbodemegbe, V. Y.; Cheng, X.; Akaho, E. H.; Allotey, F. K., "Correlation for cross-flow resistance coefficient using STAR$\mathrm{CCM}+$ simulation data for flow of water through rod bundle supported by spacer grid with split-type mixing vane", Nuclear Engineering and Design, 285, pp. 134-149, (2015).

[8] Bieder, U., Falk, F., Fauchet, G., "CFD analysis of the flow in the near wake of a generic PWR mixing grid”, Ann. Nucl. Energy, 75, pp. 15-24, (2014).

[9] Navarro, M. A. Santos, A. A. C., "Evaluation of a numeric procedure for flow simulation of a $5 \times 5$ PWR rod bundle with a mixing vane spacer", Progress in Nuclear Energy, 53(8) p. 11901196, (2011).

[10] OpenFOAM $®$ Foundation, Software OpenFOAM, Available: http://www.openfoam.org, 28 of February, (2020).

[11] Ansys, Inc.., “ANSYS User's Guide”, ANSYS, (2011).

[12] Roache P.J., Fundamentals of Verification and Validation, Hermosa Publishers, (2009).

[13] Castro, H.F.P., Vidal, G.A.M., Vieira, T.A.S., Silva, V.V.A., Campolina, D.A.M., Barros, G.P., Veloso, M.A.F. and Campagnole dos Santos, A.A., "Numerical and Experimental Investigation of the Water Flow Through PWR Spacer Grids at the Brazilian Nuclear Technology Development Center", Nuclear Reactor Thermal Hydraulics (NURETH-18), August 18-23, (2019).

[14] SolidWorks, SolidWorks 2020 User Manual. Dassault Systèmes, Massachusetts, USA, 2020.

[15] Wagner, W., Cooper, J. R., Dittmann, A., Kijima, J., Kretzschmar, H. J., Kruse, A., Mares, R., Ogushi, K., Sato, H., Stöcker, I., Sifner, O., Takaishi, Y., Trübenbach, J., Willkommen, Th., "IAPWS Industrial Formulation 1997 for the Thermodynamic Properties of Water and Steam", Journal of Engineering for Gas Turbines and Power - ASME, (2000).

[16] Wang, Y., Wang, M., Zhao, H. J. M., Zhang, D., Tian, W., Liu, T., Qiu, S., Su, G.H., "CFD simulation of flow and heat transfer characteristics in a $5 \times 5$ fuel rod bundles with spacer grids of advanced PWR", Nuclear Engineering and Technology, (2019).

[17] Santos, A.A.C., "Investigação Numérica e Experimental do Escoamento de Água em Feixe de Varetas Representativo de Elementos Combustíveis Nucleares de Reatores do Tipo PWR", Universidade Federal de Minas Gerais, Belo Horizonte, Brazil, November (2012).

[18] Castro, H.F.P., Vidal, G.A.M., Vieira, T.A.S., Silva, V.V.A., Campolina, D.A.M., Barros, G.P., Veloso, M.A.F. and Campagnole dos Santos, A.A., "Numerical and Experimental Investigation of the Water Flow Through PWR Spacer Grids", International Nuclear Atlantic Conference (INAC 2019), October 21-25, (2019). 